\title{
Um "Quase Santo" entre infiéis: Samuel Fritz e um surto messiânico na Amazônia Colonial
}

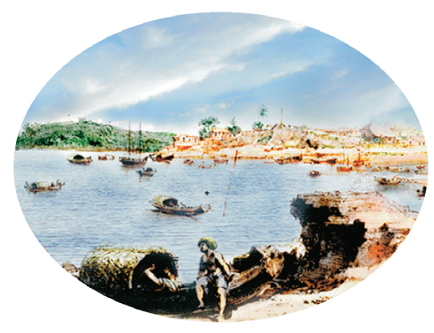

Yomarley Lopes Holanda*

\section{Resumo}

Ainda é insipiente o número de obras acerca da história regional, sobretudo àquelas centradas na formação do nosso pensamento social. "O Diário de Fritz" é uma das mais importantes fontes sobre a Amazônia Colonial. Valendo-nos da propositura de Paul Ricouer (2007), mergulhamos na leitura "profunda" do diário, objetivando desvelar o processo de construção da imagem "santa" do jesuíta junto aos povos indígenas.

Palavras-chave: História; Amazônia; messianismo.

\begin{abstract}
Yet know not the number of works on regional history, particularly those focused on training of our social thinking. The Daily of Fritz is one of the most important sources on the Amazon Colonial. Worth bringing to us from Paul Ricouer (2007), jumping in reading "deep" in the Diary, to "unveil" the process of building the image "saint" of the Jesuit with the indigenous peoples.
\end{abstract}

Keywords: History; Amazon; messianism.

\footnotetext{
*Graduado em Licenciatura em História pela UEA (2005). Mestre em Sociedade e Cultura na Amazônia pela UFAM (2010).
} 


\section{Os escritos de Fritz e sua contribuição para a formação do pensamento social sobre a Amazônia}

Tomando como referência o postulado de Paul Ricouer (2007) acerca de uma nova postura interpretativa de desvelamento daquilo que se esconde por trás das impressões, discursos e textos, pensamos em tal exercício de uma hermenêutica profunda a partir da leitura do Diário do padre Samuel Fritz (fragmentos), numa edição traduzida por Rodolfo Garcia baseada nos escritos encontrados na biblioteca de Évora (Portugal) e organizada recentemente pelo professor Ernesto Renan. Além do diário traduzido e anotado, o livro em questão traz uma cópia de seu famoso mapa e um conjunto de textos esclarecedores sobre a vida e a obra do missionário entre os índios da Amazônia. $\mathrm{O}$ argumento que norteia a construção deste artigo é o de que os escritos de Fritz trazem a lume um provável surto messiânico na Amazônia Colonial durante sua missão entre as tribos do Solimões.

O diário do padre Samuel Fritz, com suas descrições e anotações, e mesmo fragmentado em razão de um naufrágio ocorrido no rio Hondache, representa uma das pedras basilares para o conhecimento antropológico, histórico e geográfico da Amazônia. São escritos vivos, intensos e reveladores que permitem compreender o empreendimento evangelizador realizado pela Companhia de Jesus, pelo seu lado espanhol, no Grande Vale, haja vista evidenciar seus objetivos e instrumentos quase sempre persuasivos usados para aldear diferentes etnias desde abaixo da boca do rio Napo até a Barra do Rio Negro. Permite-nos também conhecer boa parte da organização dos povos indígenas, seus rituais, sistemas de caça e pesca, usos e costumes. É consenso entre os estudiosos que o Diário de Samuel Fritz é um relato de resistência, uma crônica minudente em prol da defesa e legitimidade do território espanhol diante das investidas luso-brasileiras, que nos passa a imagem de um homem movido por uma fé missionária impressionante, defensor dos nativos pagãos, mas também um servo fiel dos desígnios da Coroa Espanhola. Além do diário, em 1691, com o conhecimento geográfico adquirido após um itinerário de ida e volta até Belém, ${ }^{1}$ Fritz elaborou um mapa do rio Amazonas e seus afluentes, o mais preciso delineamento cartográfico da região até então, só superado anos depois pelo de La Condamine, que na realidade estudou e aprimorou o mapa 
do jesuíta boêmio. Nas palavras do próprio padre (apud EDMUNDSON, 2006, p.175):

Para melhor conhecimento e informação geral relativos ao grande rio Marañon fiz este mapa geográfico com não pouca dedicação e esforço tendo-o navegado a maior parte de seu curso, até onde é navegável.

O professor Ernesto Renan Freitas Pinto, ${ }^{2}$ analisando a contribuição de Samuel Fritz ao pensamento social, antropológico e geográfico sobre a região, ressalta que a presença do religioso alemão é, de fato, um dos momentos essenciais de nossa história espiritual, sendo dele uma das primeiras sínteses acerca do mundo amazônico:

Este famoso Rio, o maior até então descoberto, que às vezes recebe o nome de Amazonas, às vezes de Orellana, é propriamente o Marañon, um nome que a maioria dos geógrafos (os melhores cosmógrafos lhe dão) desde suas origens e todas as suas províncias de seus cursos superiores. Nasce na lagoa Lauricocha perto da cidade de Guanuco no reino do Peru. Corre por 2.800 léguas até desembocar no Mar do Norte através de 84 bocas. Junto da cidade de Borja tem um estreito chamado o Pongo com 25 varas de largura e três léguas de comprimento de tal rapidez que se navega em um quarto de hora. Uma e outra margem da cidade de Braçamoros (desde onde é navegável) até o Mar, estão povoadas de altíssimas árvores. Tem madeira de muitas cores, caça, salsaparilha e casca que chamam de cravo, bom para guisados e molhos. Entre seus inumeráveis peixes, o mais singular é a Vaca-marinha ou Peixe-boi, assim chamado por sua semelhança.

Sustenta-se com ervas das margens e a fêmea pare e alimenta com leite os seus filhotes. É abundantíssimo de tartarugas, armadilhos (tipo de ouriço), lagartos ou crocodilos e tem algumas cobras tão disformes que chegam a engolir um homem. Em suas montanhas há tigres ferozes e javalizes, em abundância de antas e outras muitas espécies de animais com variedade de cor em suas várzeas. Está povoadíssima de inumeráveis bárbaras nações (as mais numerosas estão anotadas no Mapa) especialmente nos rios que lhe penetram; alguns dos quais tem fama de ter muito ouro. Os portugueses possuem, até a boca, algumas populações e, na do Rio Negro, um fortim (FRITZ apud PINTO, 2006, p. 198-199). 
A descrição sobre um Novo Mundo e sua gente traçada por Fritz em seu Diário é, decerto, um dos episódios inaugurais de um estilo de representação da Amazônia chamada de cronística missionária, cuja tradição remonta ao Nuevo Descubrimiento del Marañon llamado de las Amazonas, de Laureano de La Cruz. ${ }^{3}$ Trata-se de uma narrativa de viagem exotizada, ressaltando-se as experiências de perigos, a aventura e a coragem de percorrer uma terra inóspita e viver entre os gentios, copiado por inúmeros viajantes e pesquisadores posteriores. Nela percebe-se um mosaico constituído por aspectos geográficos, sociais, ecológicos e etnográficos, enquanto elementos formadores de nossa identidade geográfica exótica, selvagem - uma Amazônia naturalizada, às vezes edênica, outras vezes infernal.

Mais tarde consagrado como "Apóstolo do Amazonas", o padre Samuel Fritz, nasceu na Boêmia (Áustria), na vila de Ornavia em 9 de abril de 1654. De família nobre e já com largos conhecimentos em Filosofia e Humanidades, aos dezenove anos entra para a Companhia de Jesus, segundo o historiador amazonense Arthur Cézar Ferreira Reis (1989, p. 86):

[...] os que lhes dirigiam a formação espiritual o destinavam à cátedra de Teologia conquanto o seu desejo constante fosse o trato com os selvagens da América, na obra admirável de tirá-los da barbaria. Compreendida essa inclinação, fora mandado servir no Vice-Reinado do Peru.

A transcrição acima imediatamente nos leva a pensar na grande obstinação do missionário que desde a juventude possuía a inclinação para a evangelização dos nativos. Ora, para um jovem padre europeu, a Amazônia, ou melhor, a cristianização dos bárbaros pagãos do Novo Mundo representava oportunidade singular de realização do ideário missionário, de elevação do espírito catequista através da experiência de martirização do corpo, sobretudo, pelas intensas provações: febres altíssimas, insetos, animais peçonhentos, índios hostis, má alimentação, travessias perigosas, enfim, a floresta tropical seria o palco ideal para a conversão de selvagens em súditos, bem como para a construção de uma imagem "santa" junto à sua Ordem Religiosa e seus seguidores. Sobre este último aspecto é que lançamos nosso olhar. 


\section{Um surto messiânico na Amazônia Colonial}

Não foram poucos os religiosos europeus que se embrenharam nas matas e singraram os rios da Amazônia durante os primeiros anos da colonização, da mesma forma, não foram poucos os que perderam a vida na tarefa de conversão e redução dos nativos à condição de novos cristãos. Samuel Fritz tinha notícias da morte trágica de colegas, da fúria de algumas tribos resistentes à evangelização, das dificuldades de deslocamento na selva e no rio, mesmo assim atuou incessantemente na implantação de novas missões ao longo do rio Solimões, indicando que sua tarefa principal era justamente esta, conforme percebemos nas páginas de seu diário.

Foi numa dessas reduções do Solimões, a Missão de Nuestra Señora de las Nieves de los Jurimáguas, fundada por Fritz em fevereiro de 1689, entre a foz dos rios Jutaí e Juruá, que se passaram os mais importantes acontecimentos registrados no terceiro capítulo da terceira parte de seu diário, principalmente sua missão entre os Omágua, Jurimágua e Ibanoma, seu adoecimento e viagem ao Pará, as investidas lusitanas que demonstram a luta entre as duas potências ibéricas pela posse da terra, e a descrição de um fenômeno emblemático que caracteriza aquilo que chamamos de um surto messiânico na Amazônia Colonial. Assim escreve o padre Samuel Fritz (2006, p. 77-78):

Notável foi o que então averiguei nesta aldeia dos Jurimáguas, e foi que em um festim que celebravam, ouvi, do rancho onde pousava, tocar uma flauta que me causou tal susto que não pude sofrer seu som; mandei que deixassem de tocar aquela flauta; perguntei que era aquilo, e me responderam que dessa maneira tocavam e chamavam à Guaricana , que era o Diabo, o qual desde o tempo de seus antepassados, vinha e assistia em suas aldeias, e lhe faziam sempre sua casa apartada da aldeia, dentro do bosque, e ali lhe levaram bebidas e os enfermos para que os curasse. Fui perguntando com que cara ou figura vinha. Respondeu-me o curaca, chamado Mativa : - "Padre, não o posso explicar, só sei que é horrível, e quando vinha todas as mulheres e meninos fugiam, somente ficavam os grandes, e então tomava o Diabo um açoite, que para o fim tínhamos preparado, de uma correia de couro de Vaca-marinha, e 
nos açoitava no peito até tirar muito sangue. $\mathrm{Na}$ ausência do Diabo, o açoitador era um velho, do que nos ficaram grandes cicatrizes nos peitos. Fazíamos isto, dizem, para sermos valentes. As figuras que tomavam eram de tigre, porco e de outros animais; ora se fazia gigante, ora anão". Perguntei mais se lhes havia dito alguma coisa de mim, ou que não me admitissem, ou me matassem; respondeu que as vozes que dava não eram articuladas, "e desde que vistes - dizia o curaca - a primeira vez e plantastes a cruz, já não que vir mais à aldeia nem quer curar mais os doentes que alguns levam à sua casa; por isso a vós os levamos agora, para que recebam o Evangelho e não morram.

Além desse episódio com Guaricana no qual parece que Fritz passou a ser considerado ainda mais um "santo" pelos índios, pois só sua presença com a cruz afugentara a entidade sobrenatural da tribo (a cura dos doentes agora ficava a cargo do próprio padre), outros eventos foram relacionados à influência direta do missionário: enchentes catastróficas, águas enlameadas durante dias e até um eclipse solar passaram a ser interpretados pelos nativos como obra do jesuíta ou mesmo causados pela sua ausência nos povoados missionários. Ao que parece a presença forte e protetora de Samuel Fritz, além de seu inegável carisma pessoal junto aos povos indígenas, fez com que pouco a pouco, algumas vezes de maneira consciente, outras não, ele fosse assumindo o imenso vazio causado pela cristianização e pelo irreversível processo de inserção nativa à sociedade colonial. Nesse caso, os poderes do padre e da cruz subjugaram o poder mágico de Guaricana. Existem passagens no diário enfatizando o poder da cruz que Fritz carregava consigo sobre a mente dos indígenas, sua simples presença apaziguava conflitos intertribais, reunia novamente índios dispersos, controlava fenômenos naturais. Não só o imaginário ameríndio dos povos do Solimões foi progressivamente consagrando enormes expectativas, muitas vezes contraditórias, que envolviam a salvação e o medo em relação ao jesuíta boêmio: "É de reparar que, nessa minha descida, se levantou ao meu respeito um grande alvoroço, não só entre os gentios circunjacentes, mas até no Pará em São Luiz do Maranhão. Para uns eu era santo e filho de Deus, para outros o Diabo" (2006, p. 84). Samuel Fritz tinha plena consciência do paradoxo entre o bem e o mal construído pelos nativos sobre a sua imagem. Nesta mesma passagem do diário, o padre anota que sua fama se estende entre os próprios colegas missionários, portugueses e até negros quilombolas, para estes últimos ele seria um redentor, que haveria de ir à Angola para libertá- 
los. Ao estudar os escritos do padre Samuel Fritz, Arthur Reis (1989, p. 89) pondera que "De todos os cantos, vinham bandos, tribos inteiras procurarlhe os ensinamentos preciosos. Não houve agrupamento indígena que não lhe tornou-se rendesse homenagens". Percebemos na análise de Arthur Cézar Ferreira Reis sobre a atuação de Samuel Fritz na Amazônia, um destaque à sua figura religiosa, caridosa e defensora dos índios. O historiador amazonense analisa as missões religiosas enquanto redutos de civilidade e proteção contra os ataques sertanistas, deixando em relevo que, além do espírito catequista, Fritz possuía claros objetivos políticos e de liderança carismática.

Segundo Barros (1988) o messianismo diz respeito à crença em um salvador, o próprio Deus ou seu emissário, e à expectativa de sua chegada, que porá fim à ordem presente, tida como iníqua ou opressiva, e instaurará uma nova era de virtude e justiça. Maria Isaura Pereira de Queiroz (1965), reconhecida internacionalmente como uma das maiores especialistas no assunto, explica que o messias é alguém enviado por uma divindade para trazer a vitória do bem sobre o mal, ou para corrigir a imperfeição do mundo, permitindo o advento do paraíso terrestre, tratando-se, pois de um líder religioso e social. Uma frase de Maria Isaura (1965, p.186) é lapidar: "os movimentos messiânicos se caracterizam pela transformação que trazem ao mundo terreno". A fim de reafirmar essa posição, a autora emprega o termo "messianismo" para designar dois fatos sociais diferentes, da seguinte forma:

A crença na vinda de um enviado divino, que trará aos homens justiça, paz e condições felizes de existência; 2) a ação de um grupo obedecendo às ordens do líder sagrado, que vem instalar na terra o reino da sonhada felicidade. A crença nasce do descontentamento, cada vez mais profundo, de certas coletividades, diante de desgraças ou de injustiças sociais que as acabrunham; afirma formalmente a esperança numa transformação positiva das condições penosas de existência a se produzir (1965, p.383).

O movimento messiânico refere-se à atuação coletiva (por parte de um povo em sua totalidade ou de um segmento de porte variável de uma sociedade qualquer) no sentido de concretizar a nova ordem ansiada, sob a condução de um líder de virtudes carismáticas. As crenças messiânicas se caracterizam por uma preocupação com o fim dos tempos, catastrófico ou utópico, mas que 
gera um novo mundo. Trata-se de um pensamento metafórico, numerológico e escatológico sem abandonar questões do mundo presente. Combina concepções históricas e míticas do tempo orientado para o sobrenatural. Ainda na acepção da autora sobredita, esses movimentos messiânicos podem ser interpretados essencialmente como momentos de anomia social, ou seja, de resposta crítica à ordem social vigente.

Atualmente essa interpretação sociológica tem sido problematizada como generalizante por muitos autores que voltaram o olhar para as particularidades de cada manifestação e interpretação messiânica de mundo. Essa influência pode ser percebida na leitura do trabalho de Duglas Teixeira (1974), onde o autor, bastante inspirado pelos estudos antropológicos de Victor Turner (1974) e Marshall Sahlins (2009), ao invés de optar pelos conceitos genéricos e abrangentes pré-definidos teoricamente, parte das concepções do próprio movimento para compreender a atuação na revolta do Contestado dentro do momento histórico em que se coloca. Para Sahlins (2009) é o significado dado pelos personagens ao evento que explica as categorias e as histórias particulares e não as categorias lidas pelos teóricos que explicam rituais ou movimentos sociais. A história é estruturada, isto é, determinada por uma estrutura lógica que é preexistente ao evento e através da qual ele tem sentido. Mas, por outro lado, o evento, inserindo-se nessa estrutura, a transforma. Assim, a história passa por sua vez a ser estruturante da ordem cultural e passa a determinar a organização da práxis.

É válido conjecturar que num universo de degradação física e espiritual das etnias indígenas causada pelas invasões armadas de apresamento, pelos agentes patogênicos devastadores e pelo estabelecimento do projeto missionário europeu na Amazônia, o poder "quase santo" do padre Fritz preenchia a lacuna existencial certamente reinante entre tais nações ameríndias. Tanto que a sua recepção nas aldeias era sempre motivo de festa, danças e alaridos, sobretudo, pela curiosidade dos índios em saber se ele era mesmo um homem ou um espírito. O próprio jesuíta ajudava a aprofundar cada vez mais esse vazio através da catequese.

A fuga para "um santo asilo" que os protegessem das terríveis incursões das tropas luso-brasileiras parece ter sido uma das poucas alternativas de sobrevivência para os povos indígenas do Solimões, e a figura de um protetor corajoso, inteligente, com poderes sobrenaturais, que se martirizasse pela causa, 
deve ter permeado a imagem que eles tinham e, por sua vez, alimentado ainda mais a fama de Samuel Fritz. Em seu diário o jesuíta escreve que a fundação, assim como a transferência de várias missões no Alto Solimões se deu pelo próprio pedido dos índios, ávidos em segui-lo, caso, por exemplo, do chefe Mativa dos Jurimágua, além de outras tribos, conforme assinala Edmundson (2006, p. 167) na introdução à edição inglesa do diário.

Até no momento da morte de Fritz, seus seguidores fizeram questão de enaltecer sua posição de guia espiritual daqueles povos recém-levados à condição de cristãos, personificando definitivamente a figura mística de "quase santo", gestada e construída durante seus longos anos de apostolado no Amazonas - considerando que a tradição jesuítica na qual o padre Samuel Fritz estava integrado tinha uma clara dimensão política e institucional, havendo, portanto, a prática de escrever e registrar seus grandes feitos -, aqui Paul Ricouer (2007) nos diria que fazemos a história e fazemos história, porque somos seres históricos. Sem dúvida, o missionário boêmio escrevia seu diário para a posteridade, tendo consciência de que sua tarefa na Amazônia era grandiosa e, portanto, digna de ser lembrada pelo porvir, pela história.

\section{Considerações finais}

A leitura profunda do Diário de Samuel Fritz, assim como de alguns de seus principais intérpretes, nos leva a pensar que o jesuíta boêmio nada tinha de ingênuo, ao contrário, sua ação articulada entre a diplomacia e a manipulação dos povos indígenas, teve como um dos princípios fundamentais a manutenção da territorialidade da região pelo reino de Castela. E mais, a implantação das missões ao longo do Solimões legitimaria o domínio espanhol, afinal, onde existissem homens convertidos, súditos do rei, lá fixar-se-iam as fronteiras (humanas) entre os dois reinos litigiosos. A história ensina que os portugueses não aceitaram a ideia (com investidas cada vez mais poderosas em direção ao oeste). Contudo, ficou a marca indelével - sobretudo registrada em seu diário escrito provavelmente para prestar contas aos superiores (e, como ser histórico, também para fazer e ficar na história - quem sabe como um santo -, pensamos em Ricouer), demonstrando a grandeza de sua obra -, de um homem que parece ter se tornado uma espécie de "messias", um salvador dos povos do Solimões, que enfrentava feras selvagens (como no episódio em que quase foi devorado por um jacaré), febres, delírios e tantos outros martírios. Fenômeno 
complexo, paradoxal: vindo do Velho Mundo para pregar o advento do filho de Deus como o salvador da humanidade, ele próprio acabou se tornando um. Não há dúvida que Samuel Fritz tinha consciência do fascínio místico que exercia sobre os índios e usava-o para fins apostólicos.

Por outro lado, talvez seja melhor pensar na atuação de Samuel Fritz como a de um grande chefe indígena, talvez um herói mítico semelhante ao Poronominare dos Baré ou ao Baíra dos Parintintin, o primeiro da região rionegrina e o segundo do rio Madeira. Afinal, para os povos da região, era comum ver seus chefes como deuses, como "homens-deuses", o que não deixa de se aproximar da concepção tradicional dos personagens santos, principalmente quando eles emergem diante de um contexto histórico tingido de sangue pelo etnocídio e pela destruição cultural, caso da Amazônia naquele período. É bem possível que a necessidade de um deus, de um herói (ou no caso de um santo) que represente um ideal intangível seja maior em tempos de crise social e política.

Tendo em vista esta discussão, podemos "ler", parafraseando Clifford Geertz (1989), este evento messiânico na Amazônia Colonial como uma manifestação humana que representa interpretações de mundo onde os atores sociais subvertem a ordem social vigente e a problematizam a partir das categorias singulares com que interpretam sua atuação no mundo, sendo capazes, inclusive, de subverter tal ordem social. O surto messiânico protagonizado pelo padre Fritz (mas que também contou com a participação premente de milhares de outros indivíduos: indígenas, sertanistas, outros missionários em processos de deslocamentos, mudança, fuga, construção e destruição de aldeamentos), portanto, pode ser interpretado ao modo de Marshall Sahlins (2009) para quem frequentemente os acontecimentos históricos não são mais do que metáforas das realidades míticas dos eventos. Similarmente se insere na mesma estrutura religiosa concernente aos episódios envolvendo os Tupinambá do litoral brasileiro e as suas viagens rumo ao interior "em busca da terra sem males": longos movimentos migratórios com base religiosa liderados por caciques, em sua maioria, já cristianizados ou mesmo nascidos em aldeamentos missionários, conforme argumenta o historiador Ronaldo Vainfas (2007). Ou seja, os eventos messiânicos atinentes ao padre Fritz ocorreram justamente nas missões onde ele evangelizava, onde se espraiavam notícias sobre seus poderes místicos, onde coincidentemente ocorreram fenômenos naturais como enchentes, terremotos 
e até um eclipse e, fundamentalmente, onde a pressão luso-brasileira era mais devastadora e os índios, já com seus espíritos consumidos pela guerra desigual, mais necessitavam de um líder mágico e destemido, para, bem mais que trazêlos à cristandade, tentar salvá-los literalmente.

\section{Notas}

${ }^{1}$ Em razão de uma enfermidade (possivelmente hidropisia). Fritz ficaria detido em Belém durante vários meses, acusado de espionagem pelo Governo Português.

2 Professor da disciplina Formação do Pensamento Social na Amazônia, oferecida pelo Programa de Pós-Graduação Sociedade e Cultura na Amazônia da Ufam, no segundo semestre de 2008.

${ }^{3}$ Franciscano, da província de Quito, participou ativamente da exploração e catequese no Napo e no Alto Amazonas. Depois de historiar a viagem rio abaixo dos leigos franciscanos Brieva e Toledo (1636-37) e a exploração de Pedro Teixeira (1637-38), narra a sua própria permanência de três anos (1647-50) entre os Omágua.

${ }^{4}$ Atual cidade de Fonte Boa, interior do Amazonas (665 km de Manaus).

\section{Referências}

ABARROS, Luitgarde O. C. A terra da mãe de Deus. Rio de Janeiro, Francisco Alves, 1988.

EDMUNDSON, George. Introdução à edição inglesa do Diário de Samuel Fritz. In: PINTO, Renan Freitas (Org.). O diário do padre Samuel Fritr. Manaus: Editora da Universidade Federal do Amazonas/Faculdade Salesiana Dom Bosco, 2006.

GEERTZ, Clifford. A interpretação das Culturas. Rio de Janeiro, Jorge Zahar Editores, 1989.

PEREIRA DE QUEIROZ, Maria Isaura. Messianismo no Brasil e no mundo. São Paulo: Dominus/ Edusp 1965. 
PINTO, Renan Freitas (Org.). O diário do padre Samuel Fritr. Manaus: Editora da Universidade Federal do Amazonas/Faculdade Salesiana Dom Bosco, 2006. . Samuel Fritr: In: PINTO, Renan Freitas (Org.). O diário do padre Samuel Frit: Manaus: Editora da Universidade Federal do Amazonas/Faculdade Salesiana Dom Bosco, 2006.

REIS, Arthur Cézar Ferreira. História do Amazonas. Rio de Janeiro: Itatiaia, 1989.

RICOUER, Paul. Memória, história e esquecimento. São Paulo: Editora da Unicamp, 2007.

SAHLINS, Marshall. Ilhas de História. Rio de Janeiro: Jorge Zahar Editores, 2009. TEIXEIRA MONTEIRO, Duglas. Os errantes do novo século - um estudo sobre o surto milenarista do Contestado São Paulo: Duas Cidades, 1974.

TURNER, Victor. O processo Ritual: Estrutura e Antiestrutura. Petrópolis: Vozes, 1974.

VAINFAS, Ronaldo. História indígena: 500 anos de despovoamento. In: BRASIL: 500 anos depovoamento. IBGE, Centro de Documentação e Disseminação de Informações. 2. ed. Rio de Janeiro: IBGE, 2007 